Heidi Julien

SUNY at Buffalo, Buffalo, NY, USA

Don Latham

Florida State University, Tallahassee, FL, USA

Melissa Gross

Florida State University, Tallahassee, FL, USA

\title{
New Understandings of Current Information Literacy Instruction Practices: Informing our Scholarship and our Teaching (Paper)
}

\begin{abstract}
:
This paper examines the implications of findings from a recent survey of academic librarians with teaching responsibilities in U.S. academic libraries, for what they can suggest to library and information science scholars in terms of research questions, and for how they can inform our preparation of future librarians.
\end{abstract}

\section{Résumé:}

\section{Introduction}

One of the "red threads" running through research in Information Science is the delicate balance between theoretical and more practical research. As a discipline with a strong practice component, we scholars have an ethical and professional obligation to translate our findings for practice, and to understand the everyday experiences and challenges of practitioners. In a recursive manner, these understandings should inform further scholarship, should motivate research inquiry into issues of relevance to practitioners, and should influence our teaching of future practitioners. With these issues top of mind, this paper will examine the implications of findings from a recent survey of information literacy instructors in U.S. academic libraries, for what they can suggest to scholars in terms of research questions, and for how they can inform our teaching.

The instructional role continues to be emphasized in professional librarians' work in academic libraries (Gold \& Grotti 2013). Because even “digital natives” do not enter post-secondary educational contexts with sophisticated information searching or information evaluation skills (Gross \& Latham 2012), academic librarians continue to have significant responsibility to help students become information literate. This teaching role is complex and challenging, and has shifted over time. An online survey sent to the community of professional librarians in the U.S. who provide information literacy instruction in academic libraries provided insights into their practices and the challenges they face. This was the first such national survey conducted in that country. Data include current pedagogical methods, client groups of focus, assessment and evaluation, marketing, instructional objectives, the role of technology in instruction, the importance of relationships with faculty and administrators, and the common challenges faced by instructional librarians. The definition of information literacy used in this study comes from the Association of College and Research Libraries: 
Information literacy is the set of integrated abilities encompassing the reflective discovery of information, the understanding of how information is produced and valued, and the use of information in creating new knowledge and participating ethically in communities of learning (ACRL 2015, 3).

The survey also explored the extent to which the Framework for Information Literacy for Higher Education is being utilized by instructional librarians (ACRL 2015). The Framework operationalizes the ACRL definition of information literacy by focusing on seven threshold concepts and related knowledge practices and dispositions.

\section{Research Methods}

The following questions motivated this study:

1. What are the instructional practices of librarians with responsibility for information literacy instruction in academic libraries in the United States?

2. What are the challenges faced by these librarians in their instructional role?

3. What are some of the opportunities for improvement in information literacy instruction practice?

Data were collected via an online national survey designed in English using SelectSurvey and was intended to take no more than 20 minutes to complete. The survey was based on earlier surveys used in Canada (Julien \& Leckie 1997; Julien 2000; Julien 2006; Julien, Tan, \& Merillat 2013), but it was updated and slightly modified for the U.S. context. Participants were recruited from the ILI-L listserv, an American Library Association (ALA) listserv with approximately 6000 subscribers that focuses on information literacy instruction. Prior to participant recruitment and data collection, ethics approval for the study was obtained at the universities where the authors are employed. The survey software provided basic quantitative analyses of data and responses to open-ended items were analyzed using a qualitative content analysis method (Julien 2008). The total number of respondents was 622, although the number of respondents per survey question varied. Since the size of the population is unknown, this is not a probability sample.

\section{Results}

The survey results are only summarized briefly here. The data show that instructional librarians are committed to their teaching roles, but that they confront significant challenges. Many practices, such as goal-setting, assessment, and marketing, are informal. The main target audience is undergraduate students and the instructional foci are largely skills-based (e.g., using databases, search strategies, general library use, and use of the online catalog). Thus, there is little evidence that respondents have incorporated the threshold concepts outlined in the Framework for Information Literacy for Higher Education (ACRL 2015). This may in large part be due to the newness of the Framework, and thus changes in practice may not have had time to be fully implemented. It is exciting to see that the vast majority of respondents see connections between the concepts presented in the Framework and their responsibility to raise the level of information literacy among students. The main challenges reported by respondents are a lack of time and insufficient support. 


\section{Implications}

These data can help information science students understand the scope and challenges of daily practice, as well as stimulate discussion about how to address those challenges. Instructors of information literacy instruction courses can use the survey data showing where potential for improvements to practice exist (e.g., in assessment practice, marketing efforts, opportunities for pedagogical innovation) to inform course content decisions. In other words, these data demonstrate gaps in the skill set revealed by the respondents; these gaps should be strengthened in the preparation of pre-service librarians for the teaching role.

A wide range of future studies and research questions also arise from this study. For instance, the survey could be conducted periodically to generate longitudinal data which tracks change over time. In addition, deeper exploration of librarians' teaching roles could occur via more qualitative methods, such as focus groups and interviews. Specific research questions to be explored could include: how do instructional librarians negotiate demands for practical skill development within a practice framework based on developing conceptual understandings, and within existing institutional constraints? How do instructional librarians best demonstrate the value of their work to generate more support for instruction? What is the nature of the institutional power relationships which challenge librarians' instructional efforts? These are only a few of the multiple research questions that could motivate further research.

Because academic, workplace, and daily life success are tied to foundational information literacy skills, impactful and meaningful instruction in these skills remains critical. Thus, there is scholarly and educational value in analyzing the issues and challenges associated with instructional work.

\section{Acknowledgements}

The authors are grateful to the librarians who helped pretest the survey and those who took the time to share their experiences and insights by responding to the survey.

\section{Reference List:}

Association of College \& Research Libraries (ACRL). 2015. Framework for Information Literacy for Higher Education. Accessed June 24, 2016. http://www.ala.org/acrl/standards/ilframework

Gold, M.L., \& Grotti, M.G. 2013. Do job advertisements reflect ACRL's Standards for Proficiencies For Instruction Librarians and Coordinators?: A content analysis. The Journal of Academic Librarianship 39(6): 558-65.

Gross, M., \& Latham, D. 2012. What's skill got to do with it? Information literacy skills and self-views of ability among first-year college students. Journal of the American Society for Information Science and Technology 63(3): 574-83.

Julien, H. 2008. Content analysis. In Given, L. (Ed.), SAGE encyclopedia of qualitative research methods (pp. 120-22). Los Angeles: Sage. 
Julien, H., \& Leckie, G.J. 1997. Bibliographic instruction trends in Canadian academic libraries. Canadian Journal of Information and Library Science 22(2): 1-15.

Julien, H. 2000. Information literacy instruction in Canadian academic libraries:

Longitudinal trends and international comparisons. College and Research Libraries 61(6): 510-23.

Julien, H. 2006. A longitudinal analysis of information literacy instruction in Canadian academic libraries. Canadian Journal of Information and Library Science 29(3): 289313.

Julien, H., Tan, M., \& Merillat, S. 2013. Instruction for information literacy in Canadian academic libraries: A longitudinal analysis of aims, methods, and success. Canadian Journal of Information and Library Science 37(2): 81-102. 